\title{
Decade Experience in Pleurectomy and Lung Decortications for Chronic Empyema Thoracis
}

\author{
Nwafor Ikechukwu Andrew, Ogbudu Stephen, Eze John Chukwuemeka, Ezemba Ndubueze \\ Cardiothoracic Surgery Unit, University of Nigeria Teaching Hospital, Enugu, Nigeria \\ Email: igbochinanya2@yahoo.com
}

How to cite this paper: Andrew, N.I., Stephen, O., Chukwuemeka, E.J. and Ndubueze, E. (2018) Decade Experience in Pleurectomy and Lung Decortications for Chronic Empyema Thoracis. World Journal of Cardiovascular Surgery, 8, 165-174. https://doi.org/10.4236/wjcs.2018.810016

Received: September 4, 2018

Accepted: October 23, 2018

Published: October 26, 2018

Copyright $\odot 2018$ by authors and Scientific Research Publishing Inc. This work is licensed under the Creative Commons Attribution International License (CC BY 4.0).

http://creativecommons.org/licenses/by/4.0/

\begin{abstract}
Background: Chronic empyema thoracis is a debilitating illness with high morbidity and mortality, and is seen among all age groups in Nigeria. Objective: To review all cases of chronic empyema thoracis treated by pleurectomy and lung decortication and highlight the indications, challenges and the outcome. Materials and Method: In a 10-year period spanning 2007-2016, 90 patients with chronic empyema thoracis were admitted and managed in our institution. A retrospective study of 36 patients who underwent surgery was performed. Results: Ten patients $(27.80 \%)$ out of 36 patients had unsuccessful one month closed chest tube drainage (CTTD). Six patients (16.67\%) were referred from peripheral hospitals as chronic empyema thoracis that had failed CTTD. The remainder, $20(55.60 \%)$ were diagnosed as chronic empyema thoracis de novo. Conclusion: Chronic empyema thoracis is a very difficult disease to manage especially in developing countries like ours, where patients present very late and the requisite facilities are inadequate.
\end{abstract}

\section{Keywords}

Emyema, Developing, Decade, Pleurectomy, Decortication

\section{Introduction}

Empyema thoracis is a pyogenic or suppurative infection in the pleural space [1] [2] [3] [4]. Empyema thoracis is exudative in nature and is the commonest exudative types of pleural effusion. Most cases of empyemas complicate Community Acquired Pneumonia (CAP) or Hospital Acquired Pneumonia (HAP), but a proportion results from iatrogenic causes or develops without pneumonia' (primary empyema) [5]. Parapneumonic effusion (PPE) develops in about half of the patients hospitalised with pneumonia and their presence causes a 4 fold increase in mortality [5]. Stages in the natural course according to American Tho- 
racic Society, are outlined as: exudative, fibrinopurulent and organising phases, and are referred to as stages I, II and III respectively [6].

Empyema thoracis is associated with high mortality ranging from $6 \%-24 \%$ [5] [7] [8] [9] [10]. The incidence is increasing in both adults and children but the cause of which is yet unknown [5] [11]-[19]. Pleural infection develops in 65,000 patients in a year in UK and USA and the peak incidence of empyema in childhood is those under 5 years [20]. In USA, empyema associated hospitalisations rose by almost $70 \%$ during 2002 among children, 18 years of age or less compared to 1977. Among adults, the incidence of empyema increased significantly 1.2 fold during a 9-year period between 1995 and 2003 in North America [5].

Bacterial invasion (stasis) leads to accelerated immune reaction leading to further migration of neutrophils and activation of coagulation cascade which favours fibrin deposition and septation in the pleural space [21] [22]. The inflammatory process continues, fuelled by more bacterial death and phagocytes with specific biochemical and microbiologic changes.

Although, fibrin deposition and early angioblastic as well as fibroblastic proliferation are seen in later phases of exudative phase, these processes accelerate and heavy fibrin deposition takes place on both pleural surfaces, especially the parietal pleura. Effusion becomes purulent [23].

Collagen organisation and deposition occur on both pleural surfaces with entrapment of the underlying lung. The organised collagen on the pleura is termed a peel. Effusion at this point is grossly purulent and $75 \%$ of the volume is sediment on standing. Chronicity is characterised by: dense fibrosis, contraction and trapping of the lung and atelectasis as well as prolonged pulmonary infection, crowding of the ribs and reduction in the size of the hemithorax and occasionally scoliosis [24].

The underlying lung is usually unaffected unless the pleural fluid production began as a parenchymal problem, e.g. PTB, necrotising pneumonia, penetrating chest trauma or malignancy [23].

The chest wall and diaphragm are usually coated by the fibrous process that is typically thicker and more exuberant over the parietal area. Entrapment of lung and thoracic cage leads to restrictive ventilatory defect that is characterised by reduction of the lung volumes: Force Vital Capacity (FVC), Total Lung Capacity (TLC), Vital Capacity (VC), Force Expiratory Volume in 1 second (FEV1) and Diffusion Capacity of Carbon Monoxide (DLCO) [24].

Pulmonary vasoconstriction leads to significant reduction of perfusion of the underlying lung. Perfusion abnormalities usually exceed the reduction of ventilation of the involved lung, and this prevents hypoxia if contralateral lung function is preserved [25].

Treatment of empyema thoracis is variable historically since Hippocrates days [26] and particularly for stage III, open access, which include thoracotomy with pleurectomy and decortications as well as minimally access, i.e., video assisted thorascopic surgery (VATs) are the accepted modalities of treatment with later 
being the currently accepted standard due to lower mortality and morbidity associated with it. In our institution in a low income country, VAT is not available. The traditional open access was used in managing the patients and our experience in 10 years is hereby described.

\section{Materials and Methods}

University of Nigeria Teaching Hospital, Ituku/Ozalla (UNTH), Enugu state is a tertiary hospital and a referral center in the south-eastern Nigeria for cases of chronic empyema thoracis requiring surgical treatment. Over a 10 -year period spanning 2008-2016, 90 patients with chronic empyema thoracis were admitted and managed in our institution. Of these, $(\mathrm{n}=36,24.0 \%)$ were treated by pleurectomy and lung decortications with or without lung resections. A retrospective study of such surgical patients was performed. The hospital database in the record's department was reviewed. The data obtained and analyzed were patients' biodata, age range of patients, sex distribution, aetiological causes, surgical procedures performed, intraoperative findings, challenges and outcome as well as the complications. Exclusion criteria were those treated by closed chest tube drainage (CTTD), alone. Data were analyzed using SPSS version 16 (Chicago). Rates and proportions were calculated with $95 \%$ confidence interval (CI). The proportions were compared using students' $t$-tests. Level of significance was set at $P<0.05$.

Surgical technique: The patient is usually postioned supine and connected to cardiopulmonary monitors. Endotracheal intubation with muscle relaxation is done. Thereafter, patient is positioned either left or right lateral decubitus. Posteriorlateral thoracotomy incision is done splitting latismusdorsi and serratus anterior muscle. The chest is entered through the $5^{\text {th }}$ or $6^{\text {th }}$ intercostals space. Where there is extensive crowding of the ribs are encountered, 1 or 2 ribs are resected. Subsequently, Finochette rib spreader is applied to increase the intercostals space. Using, fingers and swab on a stick, blunt dissection is done thereby stripping the cortex from the parietal pleura laterally and medially, superiorly and inferiorly staring from the margin of the incision. Parietal pleurotomy is done to enter the pleural cavity and any remaining purulent material is sucked out. The parietal pleura is resected with scissors. Thereafter, decortication plane is developed using multiple cruciate incisions and Lahey swabs, visceral pleurectomy (decortications) is done piece meal and In the process, multiple air leakages are encountered. Where major air leakages are encountered, they are repaired.

At the end, chest cavity is lavaged with warm normal saline (0.9\%) and 2 thoracic catheters (CTTD) are inserted through the lowermost possible intercostal space. One is sited on anterior axillary line and advanced apically while the other catheter is on the posterior axillary line and is basal thereby lying on the diaphragm. The removal of the anterior CTTD is done between $3^{\text {rd }}$ to $5^{\text {th }}$ day postoperatively when air bubble has reduced significantly. The posterior CTTD is re- 
moved when the drainage is between 50 and $70 \mathrm{mls}$ in 2 consecutive days. This postoperative hospital stay is dependent on this and varies in different patients. When post decortication complication occurs, hospital stay lasts beyond 1 to 2 weeks.

\section{Results}

Table 1 shows the various causes of empyema thoracis. The highest was PPE ( $\mathrm{n}=$ 34, 37.8\%), followed by Pulmonary tuberculosis, $(\mathrm{n}=10,11.1 \%)$. The least was osteomyelitis of the vertebra $(n=1,1.1 \%)$.

Figure 1 shows the age ranges of patients that benefited from surgery. The highest were 21 - 30 and $51-60$ with $(n=10,27.8 \%)$, respectively. The least were $61-70$ and $71-80$ with $n=1,2.8$ ) respectively.

Table 2 shows the treatment modalities performed on the patients. CTTD was done for 54 patients (60\%). This is however excluded from the study and 36 patients (40\%) had pleurectomy and lung decortications). Additional treatments in some patients were marked asterisk.

Figure 2 shows the complications of surgical treatment. Post decortications empyema constituted the highest $(\mathrm{n}=4,36.4 \%)$, closely followed by diaphragmatic perforation $(n=3,27.3 \%)$. There was no recorded mortality. Two cases (18.2\%) of cardiac arrest encountered were successfully resuscitated.

\section{Discussion}

Chronic empyema thoracis is a stage III disease according to the American

Table 1. Showing the aetiology of empyema thoracis.

\begin{tabular}{cccc}
\hline SNO & Aetiology & Number & Percentage (\%) \\
\hline 1 & Parapneumonic effusion (PPE) & 34 & 37.8 \\
2 & Idiopathic & 14 & 15.6 \\
3 & Post surgical & 2 & 2.2 \\
4 & Trauma & 5 & 5.6 \\
5 & Spontaneous pneumothorax & 2 & 2.2 \\
6 & Oesophageal perforation & 1 & 1.1 \\
7 & Subdiaphgramatic infection & 3 & 3.3 \\
8 & Septicemia & 4 & 4.4 \\
9 & Osteomyelitis of ribs & 3 & 3.3 \\
10 & Breast cancers & 5 & 5.6 \\
11 & Bronchogenic carcinoma & 6 & 6.7 \\
12 & Tuberculosis & 10 & 11.1 \\
13 & Osteomyelitis of vertebrae & 1 & 1.1 \\
Total & & 90 & 100 \\
\hline
\end{tabular}


Table 2. Showing treatment procedures for the patients. CTTD: Closed Chest Tube Drainage. ${ }^{*}$ : additional treatment to pleurectomy and lung decortications.

\begin{tabular}{cccc}
\hline SNO & Surgical Procedures & Number & Percentage (\%) \\
\hline 1 & CTTD & 54 & 60 \\
2 & Pleurectomy + lung decortications & 36 & 40 \\
3 & Eloesser Flap & $1^{*}$ & - \\
4 & Modified Eloesser Flap & $2^{*}$ & - \\
5 & Clagett Procedure & $1^{\star}$ & - \\
6 & Segmentectomy & $4^{*}$ & - \\
7 & Lobectomy & $2^{*}$ & - \\
8 & Bilobectomy & $1^{\star}$ & - \\
9 & Pneumonectomy & $1^{* *}$ & - \\
\hline
\end{tabular}

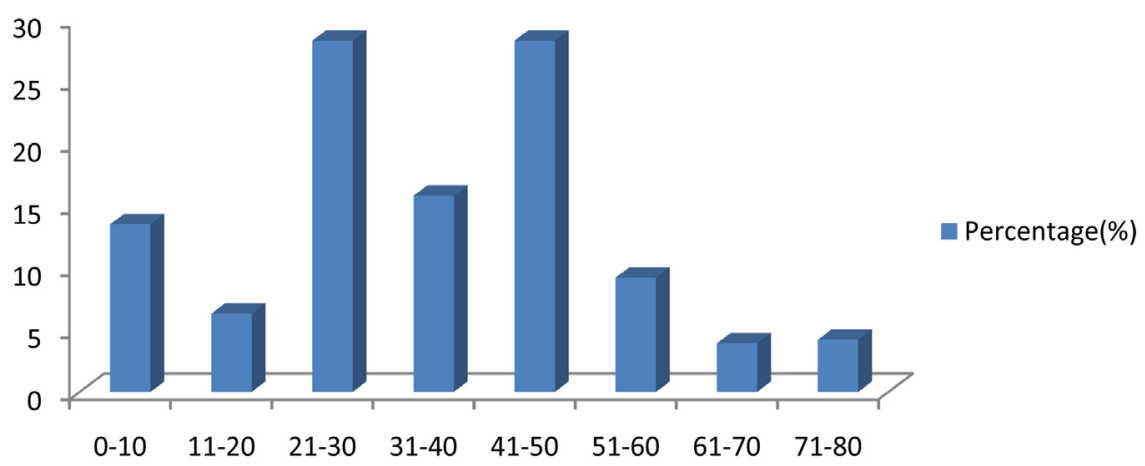

Figure 1. Age range of patients in years.

\section{Percentage(\%)}
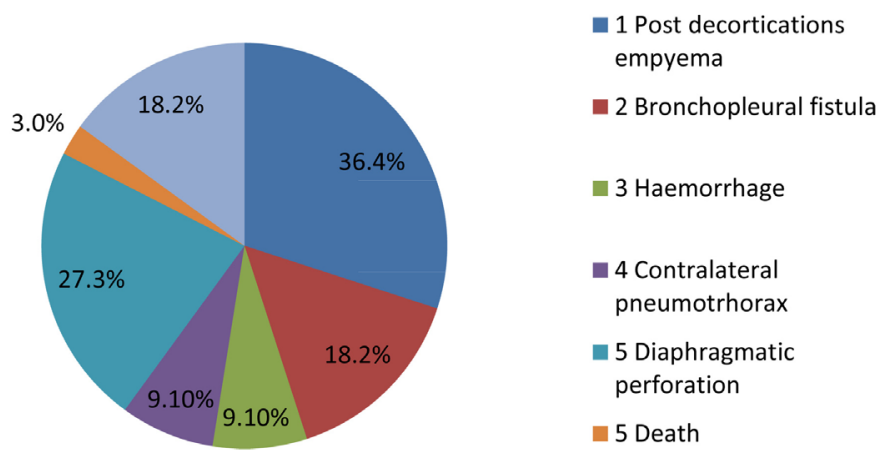

Figure 2. Shows the complications of surgical treatment.

Thoracic Society grading of empyema thoracis. The consensus opinion is that pleural empyema should be treated early to avoid complications, extensive operations and lengthy hospital stays [27] [28]. In spite of this knowledge, some patients either present or are referred late, making operative treatment inevitable. At late presentation, the standard of treatment is either videothorascopy or open thoracotomy. Videothoracoscopy has now been proposed for the treatment of chronic empyema thoracis [27] [29] [30]. However, there is yet no comparative 
study between the open and minimal accesses. Evidently, reports have shown that there are higher mortality and morbidity rates in the open procedure relative to VATS technique [30]. In the use of VATS, preoperative computed tomography is mandatory. Also, facilities and expertise for VATS are limited in low income countries. In addition, thorascopic surgery is usually inadequate and not suitable in late stages of empyemas where the encasing thick pleura needs to be removed. Indeed, majority of our patients presented in this stage.

In our study, open method was used for the procedures of thoracotomy, pleurectomy and lung decortications. Twelve out of 36 patients $(33.30 \%)$ had additional treatment, ranging from Eloesser flap, segmentectomy to pneumonectomy. Lobectomy or bilobectomy and pneumonectomy constitute an integral management of chronic empyema thoracis in a low income setting where pulmonary tuberculosis is rampant and neglected cases of empyema thoracis is not uncommon. In some of the patients, there was failure of lung re-expansion following pleurectomy and lung decortications due to underlying necrosis, cavitations or pulmonary parenchymal mass lesions. The residual spaces were managed by thoracoplasty using right superior rectus abdominis muscle flap in one patient and right serratus anterior muscle flap in another patient. The two patients did well.

The classical indications for lung resections in cases of pulmonary tuberculosis complicating chronic empyema thoracis are persistent positive sputum after 6 months of continuous optimal chemotherapy with 2 or more drugs and where drug resistant PTB has been ruled out. Some other relative indications for resections were severe cavitations, bronchiectiasis and bronchial stenosis which contributed to failure of treatment. Other relative indications as were localized parenchymal disease by atypical Mycobacterium tuberculosis with broad resistance to chemotherapy, mass lesion of the lung in areas of PTB involvement as it helped with simultaneous diagnosis of the mass lesion and treatment of PTB. Others are massive life threatening haemoptysis and recurrent haemptysis including bronchopleural fistula unresponsive to conventional CTTD. In our study, some patients with parenchymal diseases mainly due to PTB were offered lung resections ranging from segmentectomy to pneumonectomy.

In our study, aetiology of chronic emypema thoracis is shown in Table 1. Here, neglected or mismanaged, PPE was the highest $(n=34,37.8 \%)$, followed by idiopathic and PTB $(n=10,11.17 \%)$ respectively. The least were oesophageal perforation and osteomyelitis of a vertebra $(n=1,1.1 \%)$ respectively.

In the demography, the age range mostly affected were 21 - 30 and $41-50$ years $(\mathrm{n}=10,27.8 \%)$ respectively. The reason for this bimodal peak was unknown. The range of $61-70$ and $71-80$ years were the least $(n=1,2.8 \%)$; Table 2. In other studies, done in United Kingdom and North America, the age most affected was 1 - 4 years [20]. This might be connected with increased frequency of occurrence of pneumonia in that age group. However, another study, done in USA, showed an increment in adults relative to paediatric age group [5]. 
Intra-operative findings (Table 3) as seen in our study were ipislateral crowded ribs necessitating 1 or 2 rib resections before successful thoracotomy and thickened parietal and visceral pleurae $(0.2-0.5 \mathrm{~cm}$ thick). Such cases would not have yielded to VATS treatment if it were available; or lead to high procedure conversion rate.

Our complication rate was significant $(\mathrm{n}=11 / 36,30.60 \%)$. See Figure 3. Among the 11, postdecorticaion empyema was the highest $(n=4,36.4 \%)$ and is most likely due to absent negative pressure suction in the immediate postoperative period, necessitating prolonged CTTD, prolonged hospital stay and redo decorticaions. This was closely followed by iatrogenic intraoperative diaphragmatic perforations $(n=3,27.3 \%)$. This was in connection with dense adhesions. They were sorted out intraoperatively and no resultant morbidity emanated there from. Contralateral pneumohorax necessitating institution of CTTD on the contralateral hemithorax was in 1 patient $(9.1 \%)$. Also prolonged haemorrhagic effusion necessitating multiple allogenic blood transfusions was in 1 patient $(9.1 \%)$. There was no recorded mortality. However, 2 cases of cardiac arrest

Table 3. Intra-operative findings.

\begin{tabular}{ccc}
\hline SNO & No of patients & Intraoperative findings \\
\hline 1 & 36 & Ipislateral crowded ribs \\
2 & 36 & Thickened parietal and visceral pleura $(0.2-0.5 \mathrm{~cm}$ thick) \\
3 & 7 & Seropurulent materials or substances (range, $200-1000 \mathrm{mls})$ \\
4 & 3 & Serosanguinopus fluid (range, $300-700 \mathrm{mls})$ \\
5 & 4 & Fribrinoid exudates (range, $500-800 \mathrm{mls})$ \\
6 & 36 & Partial or total ipislateral lung collapse \\
7 & 20 & Frank thick pus (range, $(500-3000 \mathrm{mls})$ \\
8 & 6 & Empyema necesssitans \\
9 & 2 & Destroyed lobe(s) \\
\hline
\end{tabular}

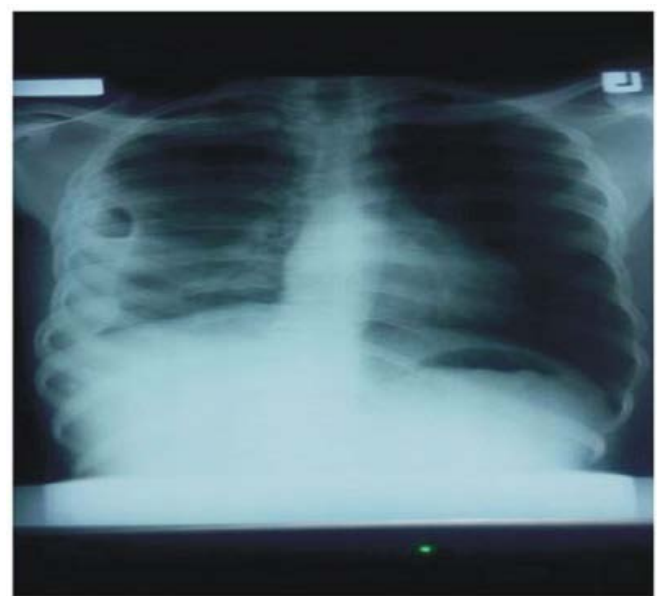

Figure 3. Shows the preoperative Chest X-ray of the patient $\rightarrow$ of the 36 patients treated surgically, sex distribution was equal; i.e., sex ratio is male: female $=1: 1$. 
were encountered in the immediate postoperative period in the intensive care unit but were successfully revived.

\section{Conclusion}

Chronic empyema is not uncommon in our subregion. Patients present late, which causes challenges in the management. Though VATS facility is not available, open thoracotomy still offers relatively good outcome. Absence of negative suction due to nonavailability of the machine, via the CTTD in the immediate postoperative period accounts for the delayed hospital stay in some of the patients. Pulmonary tuberculosis accounts mainly for the added treatment in terms of residual space closure with muscle flaps and varied types of lung resections.

\section{Conflicts of Interest}

No conflict of interest whatsoever.

\section{Declarations}

The data and materials are available at the department of Health Information Technology of our hospital and can also be obtained from the corresponding author.

\section{Funding}

There was no specific funding for this study. The authors did the study with part of their monthly salaries

\section{References}

[1] Edaigbini, S.A., Delia, I.Z., Aminu, M.B., Anumenechi, N. and Audu, S.S. (2011) Empyema Thoracis in Zaria; Preliminary Report. Nigeria Journal of Surgery, 17, 82-86.

[2] Locicero, J. (1996) Benign and Malignant Disorders of Pleura. In: Bane, A.E., Geha, A.S., Hammond, G.L., Laks, H. and Naunhein, K.S., Eds., Glenn Thoracic and Cardiovascular Surgery, Vol. 1, 6th Edition, Appleton and Lange Stanford Conneticut, 4, 537-555.

[3] Aderele, W.I. (1999) Pleural Pneumothorax and Bronchiectasis. In: Azubuike, J.C., Nkanginieme, K.E.O., Eds., Paediatrics and Child Health in a Tropical Region, Owerri, African Educational Services, 3, 246-253.

[4] Anyanwu, C.H. (2000) Empyema. In: Badoe, E.A., Achampong, E.Q., da RochaAfodu, J.T., Eds., Principles and Practice of Surgery, including Pathology in the tropics. Ghana Publishing Corporation, Tema, 1, 429-431.

[5] Ahmed, A.E.H. and Yacoub, T.E. (2010) Clinical Medicine Insights: Circulatory. Respiratory and Pulmonary Medicine, 4, 1-8.

[6] Andrews, N.C., Parker, E.F., Shaw, R.P., et al. (1962) Management of Non-Tuberculosis Empyema. The American Review of Respiratory Disease, 85, 935-936.

[7] Davies, C.W., Kearney, S.E., Glesson, F.V. and Davies, R.J. (1999) Predictors of Outcome and Long Term Survival in Patients with Pleural Effusion. American Journal of Respiratory and Critical Care Medicine, 160, 1682-1687. 
https://doi.org/10.1164/ajrccm.160.5.9903002

[8] Ferguson, A.D., Prescott, R.J., Selkon, J.B., Watson, D. and Swinburn, C.R. (1996) Empyema Subcommittee of British Thoracic Society. The Clinical Course and Management of Thoracic Empyema. QJ Med, 89, 285-289. https://doi.org/10.1093/qjmed/89.4.285

[9] Mandal, A.K., Thadepath, H. and Chettipally, U. (1998) Outcome of Primary Empyema Thoracis. Therapeutic and Microbiological Aspects. The Annals of Thoracic Surgery, 66, 1782-1786. https://doi.org/10.1016/S0003-4975(98)00601-8

[10] Asbaugh, D.G. (1991) Empyema Thoracis. Factors Influencing Morbidity and Mortality. Chest, 99, 1162-1165.

[11] Pandian, T.K., Aho, J.M., Ubl, D.S., Moir, C.R., Ishitan, M.B. and Habermann, E.B. (2016) The Rising Incidence of Pediatric Empyema with Fistula. Pediatric Surgery International, 32, 215-220. https://doi.org/10.1007/s00383-015-3834-5

[12] Gupta, R. and Crowly, S. (2006) Increasing Paediatric Admissions (Letters). Thorax, 61, 179-181. https://doi.org/10.1136/thx.2005.049510

[13] Byington, C.L., Spencer, L.Y., Johnson, T.A., et al. (2002) An Epidemiological Investigations of a Sustained High Rate of Paediatric Parapneumonic Empyema Risk Factors and Microbiological Associations. Clinical Infectious Diseases, 34, 434-440. https://doi.org/10.1086/338460

[14] Schuttz, K.D., Fan, L.L., Pinsky, J., et al. (2004) The Changing Face of Empyemas in Children: Epidemiology and Management. Paediatrics, 1139, 1735-1740. https://doi.org/10.1542/peds.113.6.1735

[15] Farha, T. and Thompson, A.H. (2005) The Burden of Pneumonia in Children in the Developed World. Paediatric Respiratory Reviews, 6, 76-82. https://doi.org/10.1016/j.prrv.2005.03.001

[16] Roxburgh, C.S., Youngdon, G.G., Towsend, J.A. and Turner, S.W. (2008) Trends in Pneumonia and Empyema in Scottish Children in the Past 25 Years. Archives of Disease in Childhood, 93, 31-38. https://doi.org/10.1136/adc.2007.126540

[17] Li, S.T. and Taurends, D.J. (2010) Empyemas Hospitalisation. Increased in US Children Despite Pneumococcal Conjugate Vaccines. Paediatrics, 125, 26-33.

[18] Finely, C., Clifton, J., Fitgerald, J.M. and Yee, T. (2008) Empyema, an Increasing Concern in Canada. Canadian Respiratory Journal, 15, 85-89.

[19] Bender, J.M., Ampofo, K., Sheng, X., Paria, A.T. and Canno-Albright, B.C. (2009) Parapneumonic Empyema Death during Past Centinary Utah. Emerging Infectious Diseases, 15, 44-48. https://doi.org/10.3201/eid1501.080618

[20] Odelowo, E.O., Adedoyin, M.A., Andy, J.J. and Olamijulo, S.K. (1989) Empyema Thoracis in Nigeriana: Experience with a Policy of Conservative Operative Treatment. International Surgery, 74, 247-252.

[21] Kroegel, C. and Anthony, V.B. (1997) Immunology of Pleural Inflammation, Potential Implications for Pathogenesis, Diagnosis and Treatment. European Respiratory Journal, 10, 2411-2418. https://doi.org/10.1183/09031936.97.10102411

[22] Idell, S., Giard, W., Koenig, K.B., McLarry, J. and Fair, D.S. (1991) Abnormalities of Pathways of Fibrin Turnover in Human Pleural Space., The American Review of Respiratory Disease 144, 187-194. https://doi.org/10.1164/ajrccm/144.1.187

[23] DeMeester, T.R. and Lafontaine, E. (1990) The Pleura. In: Sabiston, D.C. Jr. and Spencer, F.C., Eds., Surgery of the Chest, 5th Edition, Saunders, Philadelphia, 467-476.

[24] Sheshtra, K., Shah, S., Sheshtra, S., Thulung, S., Karki, B. and Porkrel, D.P. (2011) Evolving Experience in the Management of Empyema Thoracis. Kathmandu Uni- 
versity Medical Journal, 33, 5-7.

[25] Colice, G.L., Curtis, A., Deslaurier, J., et al. (2000) Medical and Surgical Treatment of Parapneumonic Effusions. Evidence-Based Guideline. Chest, 118, 1158-1171.

[26] Kergin, F.G. (1955) Treatment of Chronic Pleural Empyema. Hunterian Lecture Delivered at the Royal College of Surgeons of England on 28th July 1955. Annals of the Royal College of Surgeons of England, 17, 271-290.

[27] Cheng, Y.J., Wu, H.H., Chou, S.H. and Kao, E.L. (2002) Videoassisted Thoracoscopic Surgery in the Treatment of Chronic Empyema Thoracis. Surgery Today, 32, 19-25. https://doi.org/10.1007/s595-002-8107-2

[28] Soriano, T., Alegre, J., Aleman, C., Ruiz, E., Vasquez, A., Carvasco, J.L., et al. (2005) Factors Influencing Length of Hospital Stay in Patients with Bacterial Pleural Effusion. Respiration, 72, 587-593. https://doi.org/10.1159/000087366

[29] Walter, D.A. and Rentgarajan, A. (2001) Thorascopic Decortications: A Role for Video Assisted Thoracoscopic Surgery in Chronic Post Pneumonic Pleural Empyema. The Annals of Thoracic Surgery, 71, 1813-1816. https://doi.org/10.1016/S0003-4975(01)02471-7

[30] Chan, D.T., Silve, M.D., Chan, S., Tsang, D.S., Fang, B., Lee, T.W., et al. (2007) Surgical Treatment Chronic Empyema Thoracis. Is Video Assisted Thoracoscopic Surgery Better than Thoracotomy? The Annals of Thoracic Surgery, 84, 225-231. https://doi.org/10.1016/j.athoracsur.2007.03.019

\author{
Abbreviations \\ CTTD, Closed Chest tTube Darianage \\ VATS, Video Assisted Thoracoscopic Surgery \\ FVC, Forced Vital Capacity \\ TLC, Total: Lung Capacity \\ VC, Vital Capacity \\ FEV1, Forced Expiration in! Second \\ DLCO, Diffusion Capacity of Carbon Monoxide
}

